\title{
ENTREPRENEURSHIP AND TOURISM THROUGH THE LENS OF SUSTAINABILITY. CHARTING THE KNOWLEDGE BASE THROUGH BIBLIOMETRIC ANALYSIS
}

\author{
Diana Teodora TRIP \\ University of Oradea, Faculty of Economic Sciences, Doctoral School of Economics, Romania, e-mail: dianateodora.trip@gmail.com
}

\author{
Carmen Florina FAGADAR
}

University of Oradea, Faculty of Economic Sciences, Doctoral School of Economics, Romania, e-mail: carmen.fagadar@emanuel.ro

\author{
Daniel BADULESCU
}

University of Oradea Faculty of Economic Sciences, Department of Economics and Business, Romania, e-mail: dbadulescu@uoradea.ro

\author{
Alina BADULESCU* \\ University of Oradea, Faculty of Economic Sciences, Department of Economics and Business, Romania, e-mail: abadulescu@uoradea.ro
}

\begin{abstract}
Citation: Trip, D.T., Fagadar, C.F., Badulescu, D., \& Badulescu, A. (2021). ENTREPRENEURSHIP AND TOURISM THROUGH THE LENS OF SUSTAINABILITY. CHARTING THE KNOWLEDGE BASE THROUGH BIBLIOMETRIC ANALYSIS. GeoJournal of Tourism and Geosites, 34(1), 140-146. https://doi.org/10.30892/gtg.34118-629
\end{abstract}

\begin{abstract}
Tourism, entrepreneurship, and sustainability have been under the examination of this study, as we tried to map out the knowledge base yielded between the 1995 and 2020 timeframe. Bibliometric methods were employed in the analysis of articles. After analyzing the available articles, 322 articles concerning tourism and entrepreneurship, from which 14 articles on entrepreneurship and sustainable tourism were obtained. Further steps were made into refining the findings as we looked into which research streams related to sustainable tourism entrepreneurship have been in the spotlight.
\end{abstract}

Key words: tourism; entrepreneurship; sustainable tourism; sustainability; bibliometric analysis; research topics

\section{INTRODUCTION}

The importance of entrepreneurship in fostering innovation and competitiveness, increasing productivity, and generating employment, wealth, and income for public budgets is widely accepted. Implicitly, it also determined researchers' interest in discovering its forms, causes, apparition, motivators, and ability to exploiting opportunities, connections to lifestyle, successes, and failures (Hart et al., 1995; Carter et al., 2003; Shane, 2000; Santarelli and Vivarelli, 2007), and the literature is expanding every year.

In this article, we are interested in investigating the main corpus of literature on tourism entrepreneurship, as described in selected articles published during the last decades (the search query's timespan is 1995 to 2020). The aim is to review entrepreneurship research in the tourism and hospitality industry at large and, more specifically, in sustainable tourism, and provide future research directions. Specific objectives addressed include to examine the research themes and identify directions of research; to assess the attention given to research on entrepreneurship and sustainable tourism; to capture the research streams related to tourism entrepreneurship that have been in the spotlight; to find out how are research themes pertaining to tourism entrepreneurship clustered and what is the place for sustainability; to highlight the research gaps and future streams of study that are likely to emerge in economic studies. Such endeavor is an important one; through the bibliometric method presented here and the gaps and future trends it helped identify, the syste matic mapping of the knowledge base will enable future researchers to expand the state of the art of various fields of research and to develop their studies in a way that will truly bring out significant contributions to the knowledge base. Therefore, the research con tributes to the expansion of the frontiers of science by promoting inquiry into relevant and leading-edge topics.

The paper is organized as follows. In the second section, we present current directions identified in the literature; in the third section, we present the methodology employed, in the fourth section, we describe and discuss the findings, including a visualization of the results; in the final section, we conclude and present the main implications and limitations of the study.

\section{MATERIAL AND METHODS}

\section{Current directions in the literature on tourism entrepreneurship}

According to Ratten (2019), tourism entrepreneurship is an attractive and stimulating research topic, including the analysis of general entrepreneurial traits (risk-taking, openness to both innovation and hard work, ambition, a proactive attitude), within a captivating framework (tourism as a human interest), and multidisciplinary concepts such as the impact of technology, economic geography, cultural contact, and international relations. Due to the relatively easy identification of tourism entrepreneurs' traits with lifestyle factors (e.g., seeking a balance between the private life and managing a business, appreciating comfort and cultural/environmental factors or interpersonal relations, the rather small size and low growth rate of businesses), most studies in the last 3-4 decades subscribed to this concept of the lifestyle entrepreneur (Ateljevic and Doorne, 2000), based on case studies and the analysis of small and medium businesses, i.e., small tourism entrepreneurs (Morrison et al., 2010; Thomas et al., 2011; Badulescu and Badulescu, 2012), which combine elements of survival and growth, promoting new products and destinations, sustainability, forms of tourism that would revitalize mountain and rural areas, neglected by sweeping industrialization (Cunha et al., 2018; Badulescu and Badulescu, 2017).

The importance of education (from the point of view of both supply and consumption), the problems of resilience and succession in family businesses (typical for small and medium tourism businesses), relations with corporate entrepreneurship (large hotel chains and tour operators) were also studied. The connections to economic geography, social and anthropological analyses, all generated interest in

\footnotetext{
* Corresponding author
} 
understanding the relationship between tourism, entrepreneurship, territorial planning and regional development (Williams et al., 1989), cross-border cooperation (Timothy, 1998; Badulescu et al., 2014), and socio-cultural, religious, ethnic influences on tourism and hospitality businesses. Some studies also integrated sustainability in a broader and more humanitarian view, stressing the importance of solving the major problems of humanity, such as the SDG objectives of tourism (UNWTO and UNDP, 2017), the preservation of local cultures and traditions, of the cultural heritage of humanity (Jeffrey, 2018), the protection of small communities, the equitable share of benefits stemming from tourism, environmental protection, etc. A somewhat newer theme refers to social tourism businesses in the sharing economy (Gössling and Hall, 2019), the merging of social concerns with unique experiences in the touristic offer (Kasim, 2006), or growing tourism partnerships leading to value co-creation (Kallmuenzer et al., 2019). Alegre and Berbegal-Mirabent (2016) or Aquino et al. (2018) are suggesting Tourism social entrepreneurship as a solution and a strategy to address social issues.

The attempt to understand what was published regarding tourism in the last half-decade contains a predictive endeavor (Fagadar et al., 2021). Researchers, practitioners, academia, policymakers, and other stakeholders wish to foresee entrepreneurial research evolution in this peculiar, dynamic, complex, and fragile sector. A few trends are apparent for the next 20-30 years, as follows:

(a) A first trend can be recognized now in more holistic approaches to tourism entrepreneurship through business model proposals (Reinhold et al., 2017; Ratten, 2019; Fissi et al., 2020).

(b) A second trend takes into account the revolutionary transformations determined by technological innovation and the expansion of ITC, which stimulated the emergence of a new and ripe-for-studying field of tourism entrepreneurship, the so-called sharing economy. For over two decades, digital technology is transforming an important part of the tourism industry, generating a more dynamic character (Buhalis et al., 2019), challenging and stimulating entrepreneurs and their efforts to reanalyze and reinterpret the complex relationship between the dynamism of technological innovation, the business world, and tourism consumption.

(c) A third research direction refers to new players in the tourism industry, referred to as "new innovative tourism providers" or disruptive innovators (Guttentag, 2015), such as Airbnb, standing at a crossroads between corporate entrepreneurship, technological innovation, and consumer involvement in the touristic product's configuration;

(d) A fourth direction focuses on new approaches in the general theory of entrepreneurship, such as dynamic capabilities (D'Annunzio et al., 2015; Rodríguez et al., 2020) and entrepreneurs' capability to employ local physical and non-material resources in a more sustainable manner (Yachin and Ioannides, 2020), known as entrepreneurial bricolage (Fisher, 2012) or self-efficacy (Kornilaki et al., 2019), or the role of artificial intelligence in small and medium enterprises in tourism.

(e) Future studies could fuse fundamental theoretical perspectives into a more creative and productive approach (Solvoll et al., 2015; Ratten, 2019). It is apparent that, while many researchers studying entrepreneurship have shown openness towards the tourism sector, the converse (tourism researchers approaching the study of entrepreneurship) is less enthusiastic.

(f) The current period put a spotlight on the extraordinary challenges of the global COVID-19 pandemic, especially its devastating effects on small and medium enterprises, as "the tourism industry has been hit hard by the necessary measures taken to contain the pandemic, and it seems unlikely that the sector will return to normalcy any time soon" (International Labour Organization, 2020), with over $60 \%$ of tourism businesses around the world being severely affected or closed. Zenker and Kock (2020) consider that current and future research on the topic must rely on the numerous articles that already analyzed the effects of other crises on tourism and travel, and, by extension, on small and medium enterprises operating in tourism: economic crises (Papatheodorou et al., 2010); social and political instability, terrorism (Sönmez, 1998); the SARS epidemic, avian flu, and other influenza pandemics (Mao et al., Lee, 2010; McKercher and Chon, 2004; Page et al., 2006), the refugee crisis (Zenker et al., 2019), boycotts and animosity (Yu et al., 2020), or other natural disasters, wars and political restrictions. Tourism entrepreneurship provides ample opportunities for practically-relevant research on the role of innovation in post-crisis recovery and the consolidation of industry (Martínez-Roman et al., 2015; Thomas and Wood, 2014), but also on the difficulties and limitations, objective or subjective, encountered by small businesses implementing innovation, collaborative action and experimentation (Pikkemaat and Zehrer, 2016; Stiubea, 2020; Sundbo et al., 2007), knowledge and technology, ecoinnovations (Pikkemaat et al., 2019), acceptance, and managing change in tourism (Buhalis and Cooper, 1998).

\section{Could sustainability give new impetus to tourism entrepreneurship research?}

The field of sustainable entrepreneurship in tourism is changing rapidly both in research and in practical action. For more than two decades, we have seen an increase in the number and diversity of studies in the field. However, it is only recently that there is a call from the scientific community and practitioners for a more robust theoretical base and better development of methodological models (Malnar and Crnogaj, 2019). According to Parrish and Tilley (2016), current methodologies in sustainable entrepreneurship are still underdeveloped, both conceptually and empirically; there are confusing areas due to "the imprecise and conflicting definitions of the concept, and the need to distinguish between sustainable tourism and the development of tourism on the principles of sustainable development" (Butler, 1999: 7).

Crnogaj et al. (2014) consider tourism to be highly dependent on entrepreneurship; in other words, it cannot survive in the long term if it is not both sustainable and entrepreneurial at the same time. Hall et al. (2010) state that research related to sustainable development and entrepreneurship is developing and could be a focal point of the future of sustainable tourism. Entrepreneurship is recognized for its contribution to the provision of sustainable products and processes, and new businesses are often referred to as a panacea for many social and environmental concerns. However, there is sufficient uncertainty about the nature of entrepreneurial motivation and how it can be conducted, which is probably why some authors consider that the main driver for improving social and environmental impacts could be regulation rather than market measures (Buckley, 2012: 528). Finally, the decline of agriculture, the migration to urban centers, the lack of economic opportunities, as well as the increasing interest in sustainability and nature make tourism, especially sustainable tourism, a necessity and an opportunity in rural areas (Lordkipanidze et al., 2005).

\section{RESEARCH METHODOLOGY}

In order to chart the knowledge base of the last decades on tourism and hospitality entrepreneurship, with a lens on sustainable tourism, as well as to test the above-mentioned research trends dawning in the timeframe selected for research (1995-2020), a bibliometric analysis was employed. This quantitative, scientometric method has gained much popularity, coupled with the development of specialized research databases (e.g., Web of Science), that make research information readily available (Cancino et al., 2017).

Bibliometric analysis is recognized as a method for measuring, studying, and monitoring scientific publications and their impact on the scientific community (King, 1987; De Oliveira et al., 2019). Among the types of information revealed by such analysis, we mention (Waltman and Noyons, 2018): scientific output data (e.g., number of publications produced by a research unit), scientific impact (e.g., number of citations received by publications), scientific collaboration (data on co-authored publications, national and international and 
university-industry collaborations), interdisciplinarity (degree of publications' interdisciplinarity based on the fields cited by the publication).

The research questions we address in the analysis are as follows:

$R Q 1$. Which research streams related to tourism entrepreneurship have been in the spotlight?

$R Q 2$. What is the place of sustainable tourism entrepreneurship theme among the research conducted so far?

$R Q 3$. How are research themes pertaining to tourism entrepreneurship clustered, and what streams of study are likely to emerge in economic studies?

Bibliometrics makes use of a range of indicators and tools that combined allow for the mapping of the state of the art, identification, grouping, and analysis of research gaps and trends. De Oliveira et al. (2019) propose a process for mapping the knowledge base through bibliometric analysis, which has also been undertaken for the study herein.

\section{Defining the field of study}

As presented in the Introduction, we propose to study the tourism entrepreneurship state of the art through the lens of sustainability. We will crisscross the two major fields of entrepreneurship and tourism, studying them from the edges towards the core of our study, the common denominator of sustainability, to see the research interest captured by this complex, three-faceted field.

\section{Defining search platforms}

Weighting on the decision on search platforms, e.g., Scopus, Web of Science, we have chosen Web of Science as the right platform for this research. WoS is credited with having the most robust databases, the oldest and most comprehensive records of citation indexes, with reasonable availability of search filters, encompassing a useful analysis tool (De Oliveira et al., 2019; Ellegaard and Wallin, 2015). The bibliometric data offered by the WoS platform is the year of publication, research areas, types of documents, keywords, language, articles, authors, journals, institutions, countries, and journal JCR index.

\section{Mining of bibliometric data and importing data}

The bibliometric data mining follows a well-established process, from defining the search criteria and the search query formula to refining and exporting results. The main field of study assumed by this research involved the use of the two main terms - tourism and entrepreneurship - for the search of all scientific papers studying these two concepts. Thus, the following search profile was established in WoS:

\section{("entrepreneurship" OR “entrepreneurial" OR “entrepreneur") AND “tourism"}

This search profile, although not exhaustive, yielded a comprehensive number of scientific documents for further study. We must mention here that, although not specifically stated, this search profile, specifically the results that were yielded, include all research pertaining to sustainability. The search results have been treated with a series of refinement criteria.

The timeframe criterion was completely liberalized; our interest was manifested for the whole period of platform indexation. The results spanned from 1995 to 2020 (21st of June 2020, was the date of the search query). The language criterion - results expected were limited to the English language. Document types - articles (book chapters and proceedings have been excluded). The WoS categories considered for the search were hospitality, leisure, sport tourism, management, business, and economics. Research areas are Business economics.

Following the search and refinement stage, 322 list items were obtained. For each publication, the full record, including cited references, was obtained. The bibliometric analysis followed two important phases. The data obtained is analyzed with the help of two pieces of software - HistCite and VosViewer. While HistCite has a data analysis role, VosViewer uses visualization to underline distinctions and bring refinement to the analysis. To perform the bibliometric analyses, the first software we employed was HistCite software, a quantitative method for analyzing systematic literature reviews (Zupic and Čater, 2015). The tool is used to gain a clear view of the structure of a specific field (Garfield et al., 2006; Zupic and Čater, 2015). The software's main purpose is to make it accessible for researchers and authors to perform bibliometric analysis (Bankar and Lihitkar, 2019) by identifying the most significant authors, journals, cited references, institutions, and countries (Thelwall, 2008). Bibliometric visualizations represent a powerful way of drawing detailed information from the analysis and presenting overviews of data from multiple sources, showing developments over specific time frames, revealing clusters and connections (i.e., network analysis). The visualization software chosen for this research was VosViewer Software (Van Eck and Waltman, 2011). From the variety of analyses and visual representations that VosViewer is known for, we chose the bibliographic coupling and cartography analysis. Results are presented in visual form, revealing the research clusters.

From the data obtained following the search query, a subset of data was retrieved, namely the entrepreneurship and sustainable tourism research data, which was compared and contrasted through the same type of analysis in order to answer RQ2. For retrieving this subset of data, we built upon the already conducted stages of the analysis and selected the articles that made use of this keyword, reflected in the keyword co-occurrence analysis. The size of the subset allowed us to evaluate each article.

\section{RESULTS AND DISCUSSION}

The HistCite results reveal that between 1995 and 2006, there were published only nine research articles. From 2007 to 2020,313 papers were published, with 235 of these in the last five years). This finding indicates that tourism entrepreneurship is quite a new field of research and upholds the fact that, before 2006, tourism entrepreneurship was in the evolutionary stages of the concept. The ascending number of annual publications points out that the subject began to represent an area of interest for authors.

Table 1. Title terms by the count of publications (Source: retrieved from HistCite)

\begin{tabular}{|c|c|c|c|}
\hline No. & Word & Publications & Percent \\
\hline 1 & Tourism & 274 & 85.10 \\
\hline 2 & Entrepreneurship & 198 & 61.50 \\
\hline 3 & Innovation & 91 & 28.30 \\
\hline 4 & Business & 90 & 28.00 \\
\hline 5 & Performance & 86 & 26.70 \\
\hline 6 & Entrepreneurial & 70 & 21.70 \\
\hline 7 & Social & 65 & 20.20 \\
\hline 8 & Development & 62 & 19.30 \\
\hline 9 & Management & 60 & 18.60 \\
\hline 10 & Industry & 55 & 17.10 \\
\hline
\end{tabular}


The ranked Word List generated by HistCite displays the vocabulary taken from the document's title and excludes words with two characters or less and stop words. We choose to rank the words by the count of the publications in which they are title terms (Table 1). It is not a surprise that the terms Tourism and Entrepreneurship got the top scores of the title terms, as they were also part of the search profile. Ranked third, fourth, and fifth, we see Innovation, Business, and Performance.

With the use of the visualization software, further steps into mapping the tourism entrepreneurship knowledge base were made as we approached RQ1. In order to determine the research topics that have been addressed during the last decades on tourism entrepreneurship, we looked into the occurrence of keywords, a tool or analysis within VosViewer that quantifies terms and themes studied within the articles. Starting with a number of 1,532 keywords within the collection, and after applying a limiting factor of 3 minimum number of occurrences, 207 keywords met the threshold. The co-occurrence analysis revealed a list of classified terms on two criteria - the number of occurrences and total link strength. Figure 1 represents an overlay visualization of the analysis. While the size of circles and the labels show the higher number of keyword occurrences, the thickness of the lines shows the strength of the co-citation links. In this display, the data is reviewed against a timeline, as the color code details. Thus, we can see that themes such as innovation, performance, hospital ity, strategy, growth have been researched and cited more extensively than others. Moreover, of more recent interest to scientific research (yellow color - the year 2018 as average publication date) have been themes such as sustainability, tourism clusters, entrepreneurial marketing, uncertainty, entrepreneurial impact, social entrepreneurship, networks.

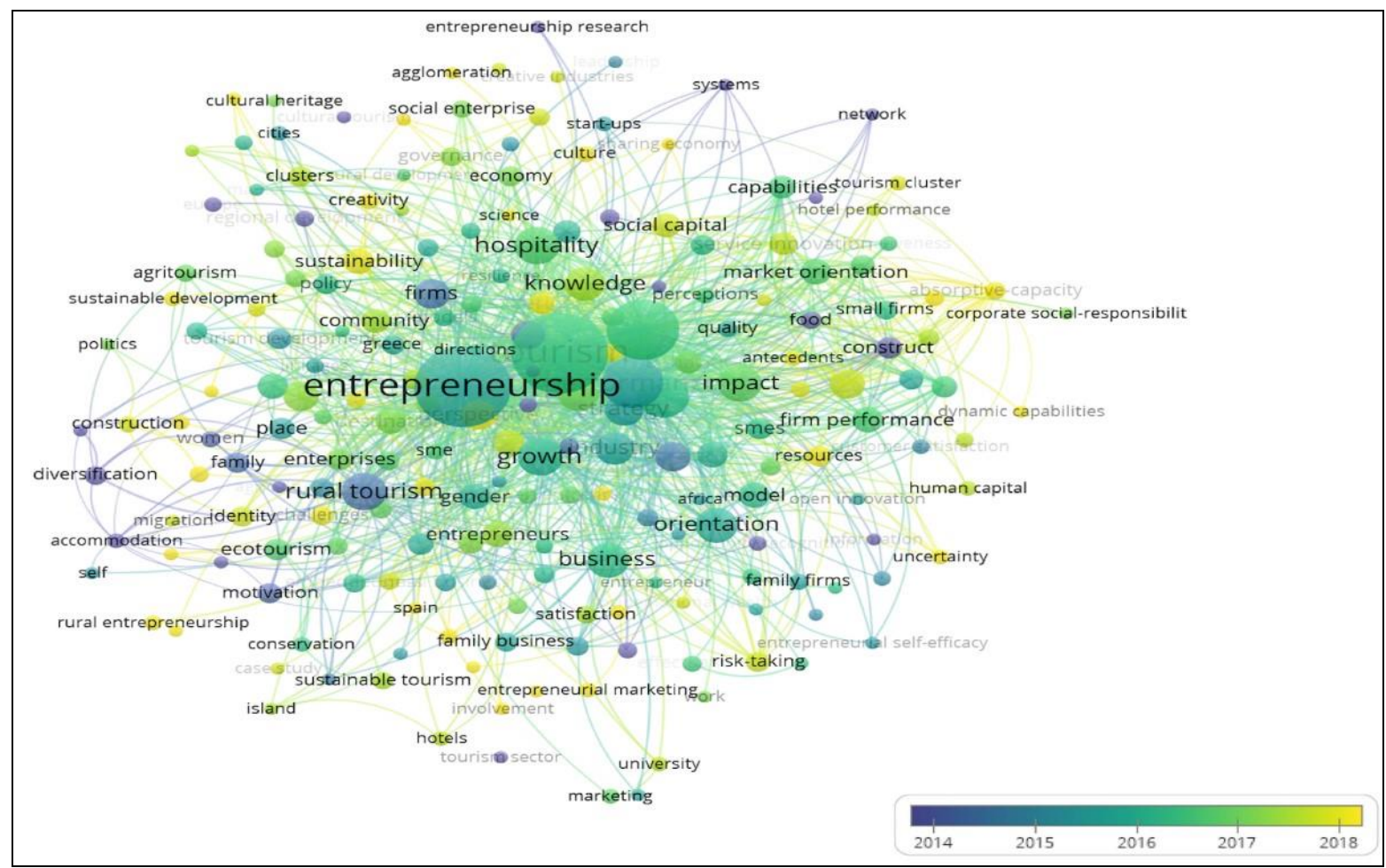

Figure 1. Keywords co-occurrence network in the "overlay visualization" display mode (Source: retrieved from VosViewer)

Research Question 3 looks within the entrepreneurship tourism research collection and attempts to see what is the place of sustainable tourism; how much has it been published, what authors, articles, and journals dealt with the theme, what papers are the most cited.

Within the 322-article collection, only a fragile sub-set of articles has been identified as looking at sustainable tourism. The sub-set contained 14 published articles written by 34 authors, with the first article having appeared in 2008. Although in small numbers, the trend is growing, with each year revealing an increasing number of published works on the relationship between entrepreneurship, tourism, and sustainability, hinting towards an increasing interest in this research topic. In our findings, there are 12 journals related to sustainability issues in tourism entrepreneurship. One journal has published three articles, and each of the others has published only one article. As we can see in the following list, not all the journals are specialized on this topic, but these results signal growing interest in it.

1. International Journal of Contemporary Hospitality Management - 3 articles

2. Amfiteatru Economic - 1 article

3. Journal for International Business and Entrepreneurship Development - 1 article

4. Journal of Destination Marketing \& Management -1 article

5. Journal of Hospitality and Tourism Management -1 article

6. Journal of Science and Technology Policy Management - 1 article

7. Regional Studies -1 article

8. Retos - Revista de Ciencias de la Administracion Y Economia - 1 article

9. Systems Research and Behavioral Science - 1 article

10. Technological and Economic Development of Economy - 1 article

11. Tourism Management - 1 article

12. Transformations in Business \& Economics -1 article

After listing the journals, we wanted to identify the most cited paper in our collection (Table 2). According to HistCite report, there are 833 cited references for our collection. Two of the first ten most cited papers have each four citations, another two papers have each three citations, and more than 50\% of top-10 papers have each two citations, meaning either they are not relevant to be cited or, in some cases, the articles are relatively recent and had no time to be cited. Contrasting the results obtained on this narrowing lens with the results of the main query (entrepreneurship and tourism), which is the objective of RQ2, we noticed that there is little to no overlap in terms of main authors, publications, and journals. Nevertheless, it is obvious that there is a growing trend in research publication for sustainable tourism entrepreneurship. 
Research Question 3 (How are research themes pertaining to tourism entrepreneurship clustered, and what streams of study are likely to emerge in economic studies?) is scrutinizing the literature in order to get more insights into the research gaps and future trends regarding the study of tourism entrepreneurship. Using VosViewer, a network visualization based on the same co-occurrence of terms analysis was constructed (Figure 2), which reveals the themes researched and the connection between them grouped into clusters. Clustering is accomplished in VosViewer on the basis of an optimization algorithm, and the number of clusters is determined by a resolution parameter.

Table 2. The most cited papers in the collection (Source: retrieved from HistCite)

\begin{tabular}{|c|l|c|}
\hline No. & \multicolumn{1}{|c|}{ Authors/Year/Title/Journal } & $\begin{array}{l}\text { Publications that } \\
\text { cited the article }\end{array}$ \\
\hline 1 & Buckley, R. (2012). Sustainable tourism: Research and reality. Annals of Tourism Research & 4 \\
\hline 2 & Butler R.W. (1999). Sustainable tourism: A state-of-the-art review. Tourism Geographies & 4 \\
\hline 3 & Lordkipanidze, M., et al. (2005). The entrepreneurship factor in sustainable tourism development. Journal of Cleaner Production & 3 \\
\hline 4 & Mair, J., Marti, I. (2006). Social entrepreneurship research: A source of explanations, prediction, and delight. Journal of World Business & 3 \\
\hline 5 & $\begin{array}{l}\text { Alegre, I., Berbegal-Mirabent, J. (2016). Social innovation success factors: hospitality and tourism social enterprises. International } \\
\text { Journal of Contemporary Hospitality Management }\end{array}$ & 2 \\
\hline 6 & Beaumont, N., Dredge, D. (2010). Local tourism governance: a comparison of three network approaches. Journal of Sustainable Tourism & 2 \\
\hline 7 & Boluk, K.A. (2011). Revealing the Discourses: White Entrepreneurial Motivation in Black South Africa. Tourism Planning \& Development & 2 \\
\hline 8 & Crnogaj, K. et al. (2014). Building a model of researching the sustainable entrepreneurship in the tourism sector. Kybernetes \\
\hline 9 & Eisenhardt, K.M. (1989). Building theories from case study research. The Academy of Management Review & 2 \\
\hline 10 & $\begin{array}{l}\text { Ergul, M., Johnson, C. (2011). Social entrepreneurship in the hospitality and tourism industry: An exploratory approach. The } \\
\text { Consortium Journal }\end{array}$ & 2 \\
\hline
\end{tabular}

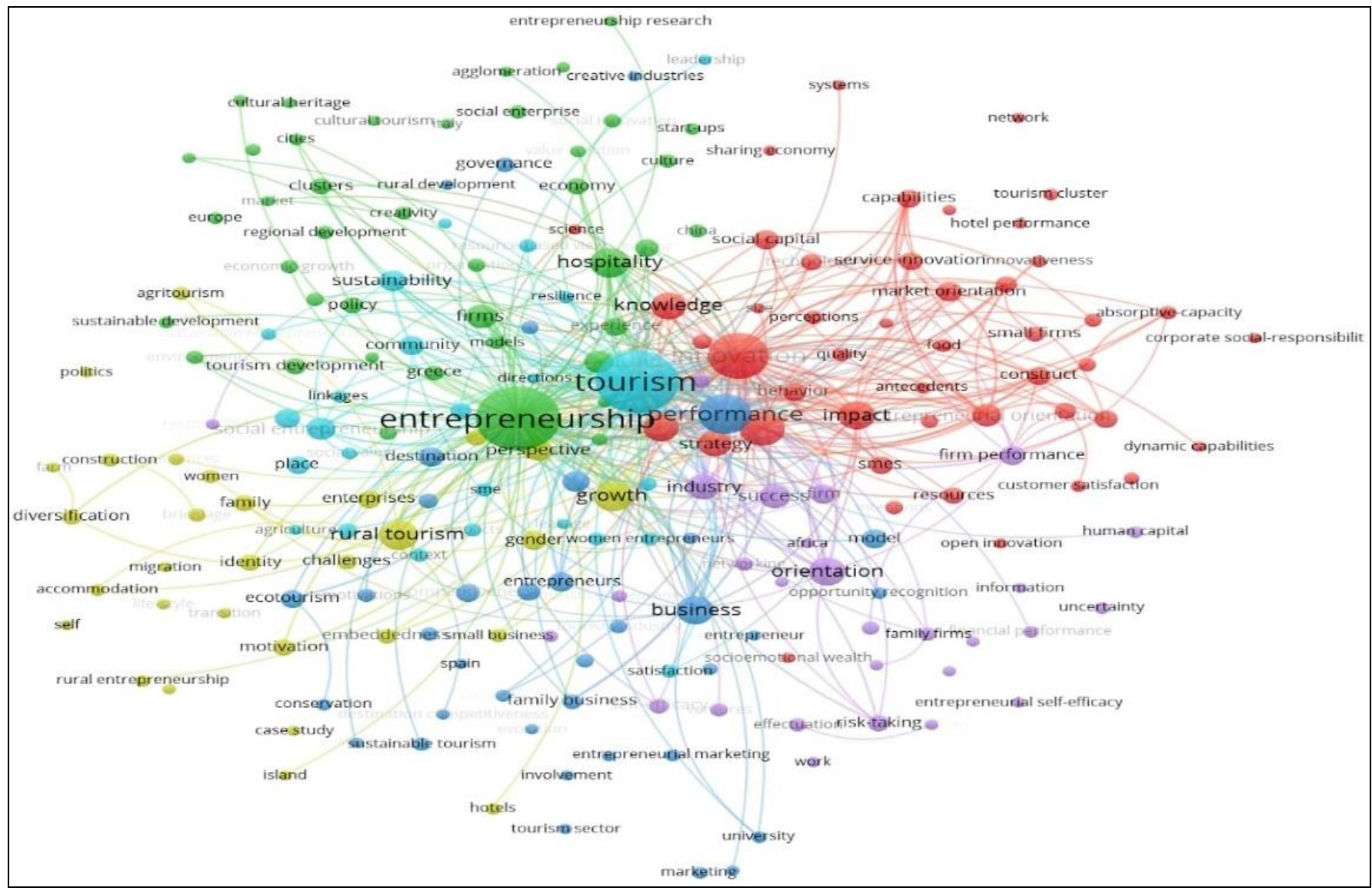

Figure 2. Keywords co-occurrence network in the "network visualization" display mode (Source: retrieved from Vos Viewer)

The clustering process revealed a number of six color-coded clusters. The zooming and exploring functionalities of VosViewer allow for easier identification of gaps and potential future streams of study.

- The red cluster, which we may call the innovation cluster, reveals less attention given to themes like corporate social-responsibility, tourism cluster, and sharing economy. However, from Figure 2, we can see that these themes have been researched quite recently, and as we have seen from the literature review, the trend might continue.

- The green cluster, which we may call the entrepreneurship cluster, reveals gaps in themes such as social innovation, clusters, cultural heritage, and sustainable heritage.

- The purple cluster, which we may call the industry cluster, reveals gaps regarding themes such as uncertainty, human capital, entrepreneurial self-efficacy, and risk-taking.

- The blue cluster, which we may call the business cluster, reveals less research regarding models, governance, competitiveness, entrepreneurial marketing, sustainable tourism, family business.

- The light blue cluster, which we may call the tourism cluster, shows disparities in researching resilience, sustainable entrepreneurship, and even leadership.

- The yellow cluster, which we may call the perspective cluster, shows little attention given to themes such as rural entrepreneurship, bricolage, lifestyle, small business. 


\section{CONCLUSIONS, IMPLICATIONS, AND LIMITATIONS}

Since the beginning of research on sustainable entrepreneurship in tourism, many authors have made considerable contributions in developing this field, commonly characterized as one of apparent confusion and immaturity. Whichever perspective is taken, a mix of approaches have been used to interpret the results, through various lenses. The purpose of the present study is to assign clarity to the relationship between entrepreneurship, tourism, and sustainability, along with identifying future research trends. For this, a 25-year bibliometric analysis was conducted on the literature on entrepreneurship tourism issues published in Web of Science between 1995 and 2020. The analysis of the leading authors, journals, scientific papers, and keywords indicates that sustainability is becoming a strategic approach for tourism and highlights the importance of this subfield within the entrepreneurial tourism literature.

Through the visualization software, the main research themes addressed so far were presented within a network context. Themes such as innovation, performance, hospitality, strategy, growth have been researched and cited more extensively than others. The number of links and the total link strength among the network' items also revealed gaps in research and potential future trends. After looking at the subset of data on sustainable tourism entrepreneurship, results acknowledged that there is almost no overlap in terms of the main authors, publications, and journals that have been identified as influential on both sets of data. The literature found on sustainable tourism entrepreneurship presents a structure with a small number of papers. Six main clusters of themes pertaining to tourism entrepreneurship have been identified: the innovation cluster, entrepreneurship, industry, business, tourism, and perspective clusters. Sustainability appears as a stream of study likely to emerge in the entrepreneurship cluster and in the business cluster (as sustainable tourism).

The present study brings its contributions both for researchers and practitioners. From the academic perspective, the bibliometric analysis offers answers to important questions that authors should ask themselves when studying the field of sustainable entrepreneurship in tourism. For practitioners in the tourism field, this study helps them understand how to integrate sustainability in their responses to environmental challenges and tourism trends. With the gaps and trends identified through the bibliometric research, we can acknowledge the points underlined in the literature review as areas either in need of more comprehensive studies or as hot spots in future research - even both. The uniqueness of the times lived now, a worldwide pandemic, which has affected in a major way the tourism sector makes this research a welcome map of the tourism entrepreneurship knowledge base and a backdrop for future similar endeavors. Although the research has particularly focused on finding all published articles in WoS having tourism and entrepreneurship keywords in the title, the keywords, and abstract, there could be other relevant studies of tourism entrepreneurship, which did not meet the search criteria. The main limitations come from the selected platform (i.e., Web of Science), research type (i.e., articles), and language of publications (i.e., English). Having attempted a tri-fold research on tourism entrepreneurship through the lens of sustainability, we noticed a limitation arising from over scrutinizing the databases, which may have rendered fragile some of the results. Another limitation of the study comes from the way a network visualization may lend qualitative significance or insignificance to certain items because of a time-related bias. In order to refute such errors, corroboration with the overlaying visualization, which has the capacity to accommodate the time frame criterion, is recommended.

While the scope of this research has been clearly delineated, future research on the field of sustainable entrepreneurship in tourism can increase the amplitude of the study by adding other scientific works from Scopus and similar platforms because, as the bibliometric analysis indicates, sustainability is an interesting topic for researchers in the tourism entrepreneurship field and is increasingly getting attention.

\section{REFERENCES}

Alegre, I., \& Berbegal-Mirabent, J. (2016). Social innovation success factors: hospitality and tourism social enterprises. International Journal of Contemporary Hospitality Management, 1155-1176. https://doi.org/10.1108/IJCHM-05-2014-0231

Aquino, R., Lück, M., \& Schänzel, H. (2018). A conceptual framework of tourism social entrepreneurship for sustainable community development. Journal of Hospitality and Tourism Management, 37, 23-32. https://doi.org/10.1016/j.jhtm.2018.09.001

Ateljevic, I., \& Doorne, S. (2000). Staying within the fence': Lifestyle entrepreneurship in tourism. Journal of Sustainable Tourism, 8(5), 378-392. https://doi.org/10.1080/09669580008667374

Badulescu, A., Badulescu, D., \& Borma, A. (2014). Enhancing cross-border cooperation through local actors' involvement. The case of tourism cooperation in Bihor (Romania) - Hajdú-Bihar (Hungary) Euroregion. Lex Localis - Journal of Local Self-government, 12(3). https://doi.org/10.4335/12.3.349-371(2014)

Badulescu, D., \& Badulescu, A. (2017). Rural Tourism Development through Cross-border Cooperation. The Case of Romanian-Hungarian Cross-border Area. Eastern European Countryside, 23(1), 191-208. https://doi.org/10.1515/eec-2017-0009

Badulescu,, A., \& Badulescu, D. (2012). Entrepreneurship and Local Resources. In D. Leslie (Ed.). Tourism Enterprises and the Sustainability Agenda across Europe, 151-168, Ashgate Publishing, UK.

Bankar, R., \& Lihitkar, S. (2019). Science Mapping and Visualization Tools Used for Bibliometric and Scientometric Studies: A Comparative Study. Journal of Advancements in Library Sciences, 6(1). https://doi.org/10.37591/joals.v6i1.1807

Buckley, R. (2012). Sustainable tourism: Research and reality. Annals of Tourism Research, 528-546. https://doi.org/10.1016/j.annals.2012.02.003

Buhalis, D., \& Cooper, C. (1998). Competition or co-operation? Small and medium sized tourism enterprises at the destination. In E. Laws, \& B. Faulkner, Embracing and Managing Change in Tourism, 324-346, London, UK: Routledge.

Buhalis, D., Harwood, T., Bogicevic, V., Viglia, G., Beldona, S., \& Hofacker, C. (2019). Technological disruptions in services: lessons from tourism and hospitality. Journal of Service Management, 30(4), 484-506. https://doi.org/10.1108/JOSM-12-2018-0398

Butler, R. (1999). Sustainable tourism: A state-of-the-art review. Tourism Geographies, 7-25. https://doi.org/10.1080/14616689908721291

Cancino, C., Merigó, J., \& Coronado, F. (2017). A Bibliometric Analysis of Leading Universities in Innovation Research. Journal of Innovation \& Knowledge, 106-24. https://doi.org/10.1016/j.jik.2017.03.006

Carter, N., Gartner, W., Shaver, K., \& Gatewood, E. (2003). The career reasons of nascent entrepreneurs. Journal of Business Venturing, 18(1), 13-39. https://doi.org/10.1016/S0883-9026(02)00078-2

Crnogaj, K., Rebernik, M., Bradac Hojnik, B., \& Omerzel Gomezelj, D. (2014). Building a model of researching the sustainable entrepreneurship in the tourism sector. Kybernetes, 43(3/4), 377-393. https://doi.org/10.1108/K-07-2013-0155

Cunha, C., Kastenholz, E., \& Carneiro, M. (2018). Lifestyle entrepreneurs: The case of rural tourism. In L. Carvalho, C. Rego, M. Lucas, M. SánchezHernández, \& A. Noronha (Eds.). Entrepreneurship and structural change in dynamic territories, 175-188, Springer, Cham.

D’Annunzio, C., Carattoli, M., \& Dupleix, D. (2015). Dynamic Capabilities Associated with a Firm's Growth in Developing Countries. A Comparative Study of Argentinean SMEs in the Software and Tourism Industries. Journal of Entrepreneurship, Management and Innovation, 11(4), 25-61. https://doi.org/10.7341/20151142

De Oliveira, J., Da Silva, F., Juliani, F., Ferreira Motta Barbosa, L., \& Vieira Nunhes, T. (2019). Bibliometric Method for Mapping the State-of-the-Art and Identifying Research Gaps and Trends in Literature: An Essential Instrument to Support the Development of Scientific Projects. In S. Kunosic, \& E. Zerem (Eds.), Scientometrics Recent Advances (doi:10.5772/intechopen.85856). IntechOpen, London, UK.

Ellegaard, O., \& Wallin, J. (2015). The Bibliometric Analysis of Scholarly Production: How Great Is the Impact? Scientometrics, 105(3), 1809-31. https://doi.org/10.1007/s11192-015-1645-Z

Fagadar, C.F., Trip, D.T., \& Badulescu, D. (2021). Academic Contributions in Entrepreneurship Tourism Research. A Bibliometric Analysis. Oradea Journal of Business and Economics, 6(1), (forthcoming).

Fisher, G. (2012). Effectuation, causation, and bricolage: A behavioral comparison of emerging theories in entrepreneurship research. Entrepreneurship Theory and Practice, 36(5), 1019-1051. https://doi.org/10.1111/j.1540-6520.2012.00537

Fissi, S., Romolini, A., \& Gori, E. (2020). Building a business model for a new form of hospitality: the albergo diffuso. International Journal of Contemporary Hospitality Management, 32, 307-323. https://doi.org/10.1108/IJCHM-01-2019-0047 
Garfield, E., Paris, S., \& Stock, W. (2006). HistCite: A software Tool for Infometric Analysis of Citation Linkage. Information, $391-499$.

Gössling, S., \& Hall, C. (2019). Sharing versus collaborative economy: how to align ICT developments and the SDGs in tourism? Journal of Sustainable Tourism, 27(1), 74-96. https://doi.org/10.1080/09669582.2018.1560455

Guttentag, D. (2015). Airbnb: disruptive innovation and the rise of an informal tourism accommodation sector. Current Issues in Tourism, 18(12), 1192-1217. https://doi.org/10.1080/13683500.2013.827159

Hall, J., Daneke, G., \& Lenox, M. (2010). Sustainable development and entrepreneurship: Past contributions and future directions. Journal of Business Venturing, 25(5), 439-448. https://doi.org/10.1016/j.jbusvent.2010.01.002

Hart, M., Stevensen, H., \& Dial, J. (1995). Entrepreneurship: a definition revisited. In W. Bygrave (Ed.), Frontiers of entrepreneurship 1995. Proceedings of the 15th Annual Entrepreneurship Research Conference, 75-89, Babson College, USA

International Labour Organization. (2020). The impact of COVID-19 on the tourism sector. Retrieved 07 19, 2020, from https://www.ilo.org/wcmsp5/ groups/public/---ed_dialogue/---sector/documents/briefingnote/wcms_741468.pdf

Jeffrey, H. (2018). Tourism and gendered hosts and guests. Tourism Review, available at: https://doi.org/10.1108/TR-02-2017-0024

Kallmuenzer, A., Peters, M., \& Buhalis, D. (2019). Host-Guest value Co-Creation in hospitality family firms. Current Issues in Tourism, available at: https://doi.org/10.1080/13683500.2019.1611746

Kasim, A. (2006). The Need for Business Environmental and Social Responsibility in the Tourism Industry. International Journal of Hospitality \& Tourism Administration, 7(1), 1-22. https://doi.org/10.1300/J149v07n01_01

King, J. (1987). A Review of Bibliometric and Other Science Indicators and Their Role in Research Evaluation. Journal of Information Science, 13(5), 261276. https://doi.org/10.1177/016555158701300501

Kornilaki, M., Thomas, R., \& Font, X. (2019). The sustainability behaviour of small firms in tourism: The role of self-efficacy and contextual constraints. Journal of Sustainable Tourism, 27(1), 97-117. https://doi.org/10.1080/09669582.2018.1561706

Lordkipanidze, M., Brezet, H., \& Backman, M. (2005). The entrepreneurship factor in sustainable tourism development. Journal of Cleaner Production, 13, 787-798. https://doi.org/10.1016/j.jclepro.2004.02.043

Malnar, A., \& Crnogaj, K. (2019). Sustainable Entrepreneurship and Related Destinations, Literature Review for Research Implication,. Varazdin, 24-25 October: 46th International Scientific Conference on Economic and Social Development - "Sustainable Tourist Destinations".

Mao, C.K., Ding, C., \& Lee, H.L. (2010). Post-SARS tourist arrival recovery patterns: An analysis based on a catastrophe theory. Tourism Management, 31(6), 855-861. https://doi.org/10.1016/j.tourman.2009.09.003

Martínez-Roman, J., Tamayo, J., Gamero, J., \& Romero, J. (2015). Innovativeness and business performances in tourism SMEs. Annals of Tourism Research, 54, 118-135. https://doi.org/10.1016/j.annals.2015.07.004

McKercher, B., \& Chon, K. (2004). The Over-Reaction to SARS and the Collapse of Asian Tourism. Annals of Tourism Research, 31(3), 716-719. https://doi.org/10.1016/j.annals.2003.11.002

Morrison, A., Carlsen, J., \& Weber, P. (2010). Small tourism business research change and evolution. International Journal of Tourism Research, 12(6), 739749. https://doi.org/10.1002/jtr.789

Page, S., Yeoman, I., Munro, C., Connell, J., \& Walker, L. (2006). A case study of best practice - visit Scotland's prepared response to an influenza pandemic. Tourism Management, 27(3), 361-393. https://doi.org/10.1016/j.tourman.2006.01.001

Papatheodorou, A., Rosselló, J., \& Xiao, H. (2010). Global Economic Crisis and Tourism: Consequences and Perspectives. Journal of Travel Research, 49(1). https://doi.org/10.1177/0047287509355327

Parrish, B., \& Tilley, F. (2016). Sustainability Entrepreneurship: Charting a Field in Emergence. In M. Schaper (Ed.), Making Ecopreneurs, Developing Sustainable Entrepreneurship. Routledge, London.

Pikkemaat, B., \& Zehrer, A. (2016). Innovation and service experiences in small tourism family firms. International Journal of Culture, Tourism and Hospitality Research, 10(4), 343-360. https://doi.org/10.1108/IJCTHR-06-2016-0064

Pikkemaat, B., Peters, M., \& Bichler, B. (2019). Innovation research in tourism: Research streams and actions for the future. Journal of Hospitality and Tourism Management, 41, 184-196. https://doi.org/10.1016/j.jhtm.2019.10.007

Ratten, V. (2019). Tourism entrepreneurship research: a perspective article. Retrieved 07.19.2020. https://doi.org/10.1108/TR-06-2019-0204

Reinhold, S., Zach, F., \& Krizaj, D. (2017). Business models in tourism: a review and research agenda. Tourism Review, 72(4), 462-482. https://doi.org/10.1108/TR-05-2017-0094

Rodríguez, A., Barón, N., \& Martínez, J. (2020). Validity of Dynamic Capabilities in the Operation Based on New Sustainability Narratives on Nature Tourism SMEs and Clusters. Sustainability, 12, 1004. https://doi.org/10.3390/su12031004

Santarelli, E., \& Vivarelli, M. (2007). Entrepreneurship and the process of firms' entry, survival and growth. Industrial and Corporate Change, 16(3), 455488. https://doi.org/10.1093/icc/dtm010

Shane, S. (2000). Prior knowledge and the discovery of entrepreneurial opportunities. Organization Science, 11(4), 448-469. https://doi.org/10.1287/orsc.11.4.448.14602

Solvoll, S., Alsos, G., \& Bulanova, O. (2015). Tourism entrepreneurship-review and future directions. Scandinavian Journal of Hospitality and Tourism, 15(sup.1), 120-137. https://doi.org/10.1080/15022250.2015.1065592

Sönmez, S. (1998). Tourism, terrorism, and political instability. Annals of Tourism Research, 25(2), 416-456. https://doi.org/10.1016/S0160-7383(97)00093-5

Stiubea, E. (2020). The Use of Collaborative Platforms in Romania and EU: A Comparative View. Oradea Journal of Business and Economics, 144-153. https://doi.org/10.47535/1991ojbe105

Sundbo, J., Orfila-Sintes, F., \& Sørensen, F. (2007). The innovative behaviour of tourism firms—comparative studies of Denmark and Spain. Research Policy, 36(1), 88-106. https://doi.org/10.1016/j.respol.2006.08.004

Thelwall, M. (2008). Bibliometrics to webometrics. Journal of Information Science, 34(4), 605-621. https://doi.org/10.1177/0165551507087238

Thomas, R., \& Wood, E. (2014). Innovation in tourism: re-conceptualising and measuring the absorptive capacity of the hotel sector. Tourism Management, 45(1), 39-48. https://doi.org/10.1016/j.tourman.2014.03.012

Thomas, R., Shaw, G., \& Page, S. (2011). Understanding small firms in tourism: A perspective on research trends and challenges. Tourism Management, 32(5), 963-976. https://doi.org/10.1016/j.tourman.2011.02.003

Timothy, D. (1998). Cooperative Tourism Planning in a Developing Destination. Journal of Sustainable Tourism, 6(1), 52-68. https://doi.org/10.1080/09669589808667301

UNWTO \& UNDP. (2017). Tourism and the Sustainable Development Goals - Journey to 2030. UNWTO, Madrid

Van Eck, N., \& Waltman, L. (2011). Text mining and visualization using VOSviewer. Retrieved from https://arxiv.org/abs/1109.2058

Waltman, L., \& Noyons, E. (2018). Bibliometrics for Research Management and Research Evaluation. Leiden University, Centre for Science and Technology Studies, The Netherlands.

Williams, A., Shaw, G., \& Greenwood, J. (1989). From tourist to tourism entrepreneur, from consumption to production: Evidence from Cornwall, England. Environment and Planning A: Economy and Space, 21(12), 1639-1653. https://doi.org/10.1068/a211639

Yachin, J., \& Ioannides, D. (2020). "Making do" in rural tourism: the resourcing behaviour of tourism micro-firms. Journal of Sustainable Tourism, 28(7), 1003-1021. https://doi.org/10.1080/09669582.2020.1715993

Yu, Q., Manus, R., Yen, D., \& Li, X. (2020). Tourism boycotts and animosity: A study of seven events. Annals of Tourism Research, 80, 102792, https://doi.org/10.1016/j.annals.2019.102792

Zenker, S., \& Kock, F. (2020). The coronavirus pandemic - A critical discussion of a tourism. Tourism Management, 81, 104164. https://doi.org/10.1016/j.tourman.2020.104164

Zenker, S., von Wallpach, S., Braun, E., \& Vallaster, C. (2019). How the refugee crisis impacts the decision structure of tourists: A cross-country scenario study. Tourism Management, 71, 197-212. https://doi.org/10.1016/j.tourman.2018.10.015

Zupic, I., \& Čater, T. (2015). Bibliometric methods in management and organization. Organzational Research Methods, 18, 429-472. https://doi.org/10.1177/1094428114562629 